\title{
NUMERICAL SIMULATION OF PHYSICAL SYSTEMS IN AGRI-FOOD ENGINEERING
}

\author{
Angelo Fabbri, Chiara Cevoli, Florina Aurelia Silaghi, Adriano Guarnieri
}

\section{Introduction}

The use of numerical simulation, in some industrial sectors such as chemical or mechanical, is a key factor in the ability to produce or improve products at a competitive cost and in a short time. In confined areas of industry, the numerical simulation is seen nowadays as a realistic alternative to the experimentation on prototypes [Datta 1998]. Even if the application of these methods in industry is rather recent, its feasibility is rapidly growing thanks to continuous progress in computational power and in the development of more versatile and easy to use software packages. In food and agricultural engineering, numerical models have been developed primarily for research purposes, starting with the studies of Singh [Singh 1989; Puri 1990].

The numerical model, that is the base of a simulation, consists essentially in a set of differential equations able to describe the physics of the problem, solved by a numerical method, on a geometrically defined domain.

Such a model can be thought as a representation, more or less simplified, of a physical prototype but considering the following advantages:

1 - the project can be verified or, however, refined through a procedure of subsequent trials. The behaviour of the system can be checked in extreme conditions. Furthermore a sensitivity analysis is possible, to relate process to product variables, without the costs and time effort of a complete experimental work;

2 - the process can be analysed in great detail: it is often possible to make observations essentially impossible to measure;

Paper received 18.05.2011; accepted 19.09.2011

Angelo FabBri, research assistant: Chiara Cevoli, PhD; Florina Aurelia Silaghi, PhD; Adriano Guarnieri, full professor - Department of Agricultural Economics and Engineering DEIAgra, University of Bologna, P.zza Goidanich, 60, Cesena FC. e-mail afabbri@ agrsci.unibo.it. Tel. 0039.0547338114, fax 0039.0547382348.

Dr. Florina Silaghi, made a first translation in English; Prof. Adriano Guarnieri, coordinator; ing. Angelo Fabbri and Dr. Chiara Cevoli made all the bibliographic research.
3 - the simulation can be used in the pre-design phase in order to build prototypes closer to the final design.

Currently one of the main limits to the diffusion of the numerical simulation in industry is related to the need for specifically trained staff. Even if there are also technical issues related to the peculiarities of the agricultural and food area, as:

1 - the biological materials are complex and it is not always possible to neglect their heterogeneity and anisotropy. Moreover their physical properties (e.g. density, thermal and electrical conductivity, specific heat, viscosity, permeability, moisture diffusivity, composition) can vary with temperature, humidity, deformation history and time;

2 - geometries are often irregular and different. An example might be the variability in shape and size of fruit, vegetables or animals;

3 - the different physical processes involved are often coupled.

\section{The development of a numerical model of a physical system}

The mathematical models of physical systems, as for fluid dynamics or thermodynamic problems, are usually expressed by a system of partial derivative differential equations. Usually it is not possible to find a closed form solution for these equations, but it is possible to find out an approximate solution by numerical methods. The finite elements (EF, that transforms differential equations in an algebraic system by a weighted residual method) and finite volume methods (VF, whose discretisation scheme is based on a conservation principle) are the most widely used, for their ability to deal with an arbitrary geometry.

The key of the methods is the discretisation of the calculation domain, in other words the geometry is split in simple primitive shapes (usually triangles or quadrilaterals in 2D and tetrahedral or hexahedra in 3D space) not overlapped, called finite elements or finite volumes (being very small but not infinitesimal). The elements are defined through their vertices, 
named nodes. The set of nodes and elements that describes the whole geometry is called mesh.

The spatial distribution of the physical properties of interest within the domain (e.g. strain, temperature, fluid velocity, concentration), usually expressed by equations impossible to integrate, within each element is approximated by a simple shape-function (typically linear or otherwise polynomial).

The equations related to each element are formed through a suitable physical principle (equilibrium, congruence or mass, energy, momentum conservation) generating a system of linear or locally linearised equations.

The system became completely suitable for automatic solution when the boundary conditions were assigned to nodes (e.g. constraints, loads, imposed displacements, temperature, flow rate or pressure).

Operatively the construction of the numerical model of a physical system goes through three phases, conventionally described in international literature as preprocessing, solving and finally postprocessing. In figure 1 is reported the flow chart diagram of the three phases concerning the construction of a numerical model. Typically the first step consists in the definition of the geometry, boundary conditions and material properties. This phase is the most critical for the user and often needs the major amount of time. Subsequently, the software assembles the governing equations on a discretised domain and sets up the resolution in a numerical way, this part involves most of the computation time. The final step consists in the evalu-

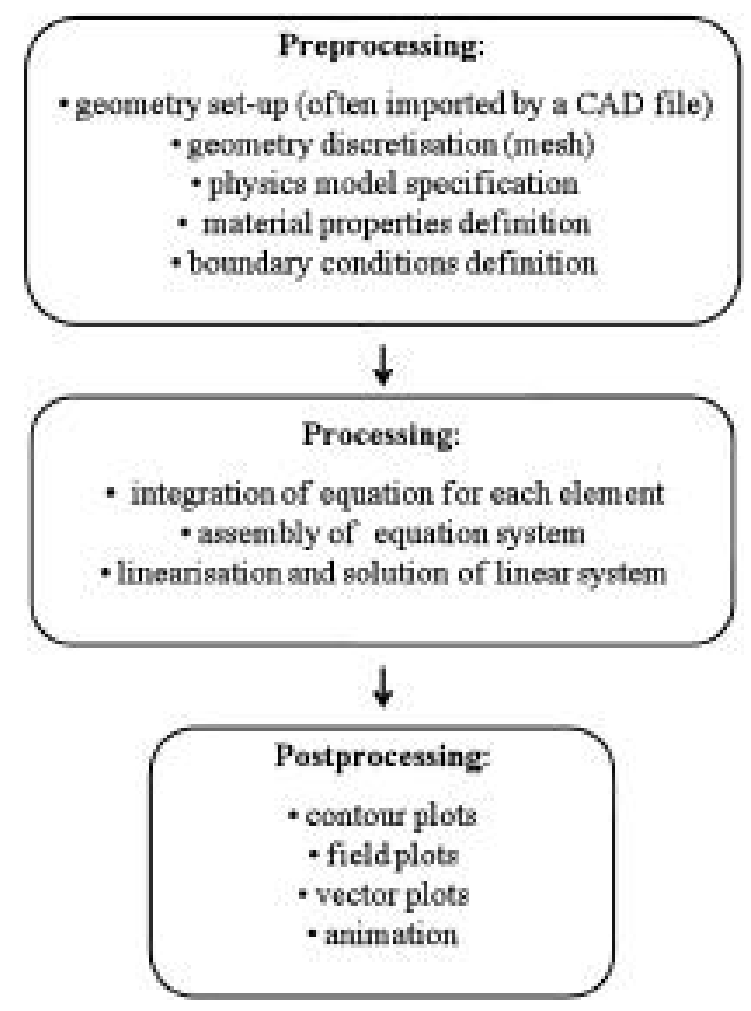

Fig. 1 - Flow chart diagram of the phases concerning the simulation model construction. ation of the solution, for example through the visual observation of scalar or vector field values (e.g. pressure, temperature, speed, voltage, displacements).

\subsection{Pre-processing: geometry definition, constitutive equations and boundary conditions}

The phase of the physical description of the model is the most creative and needs a significative experience of the developer. It is in fact necessary to understand which elements of physical reality are less important to balance the model feasibility with available computing resources, time and professional skills. At this stage it is also important to know the strength points of the different modeling software packages commercially available.

The mesh construction phase could require an active role of the researcher too, mainly when it is necessary to determine a good compromise between computational resources and quality of result, in the sense that a more refined mesh involves an increase in both accuracy of the solution and computational time (with a more than proportional law). A very useful but rare feature of some FE/FV packages is the ability to dynamically adjust the discretisation during the calculation, following geometry modifications or gradients in physical fields.

A crucial point regarding result quality is related to the possibility to consider in the model accurate material property data. This is particularly important in food technology where materials are more difficult to describe than traditional building materials used in engineering, as metal materials. The experimental characterization of involved material may be a solution to the problem. Obviously this is not always a viable way because of equipment costs and the alternative is the use of data from literature [Rahman 2009; Rao 2005; Nesvadba 2004; Houska 2001; Singh 1995; Rao 1995; Datta 1995; Okos 1986; Mohsenin 1980] or from scientific or industrial directories [Nelfood 201; MatWeb 2011; Goodfellow 2011, ESM 2011; EngineeringToolbox 2011]. The same scientific literature reports an empirical formula for the correlation between the physical properties and the composition for many heterogeneous materials [Datta 1995; Rao 1995; Okos 1986; Rahman 1996; Mohsenin 1980].

\subsection{Processing: solution of the equations}

After the setting up of the governing equation system, it is necessary to define a solution method able to provide the best results in the shortest time and under acceptable conditions of numerical stability (e.g. discretisation in time, direct or iterative solvers, implicit or explicit, based on segregated or coupled nonlinear equations). This choice is clearly influenced by the type of problem and by the specific software used. The stage of the building of discretised equation system, linearization and resolution by matrix algebra techniques, requires the greatest computational effort. 
It is not uncommon to conduct elaborations that need hours or even days.

\subsection{Post-processing: solution analysis}

The most modern FE/FV packages have different features for the graphical representation of results (false-colour graphics, cross sections, iso-value curves, vector fields, streamlines, particle tracing) that allow a detailed observation of the process, both in space and time, generally not possible only with experimentation. The phase of the results analysis often does not define the end of the calculation cycle, but suggests the changes for the next.

Moreover the comparison of the values calculated in specific conditions with experimental or literature data may be important as it permits the assessment of the model. Moreover the tuning of the model, acting on some parameters impossible to be known by the analyst, is the activity aimed to make the output of the software coincide with real data and constitutes a way of improving the model reliability. It is even possible to compare the calculated values with just experimental ones in integral form, that usually are easier to measure.

\section{Applications in agri-food engineering}

The numerical simulation methods offer a powerful design and analysis tool to agricultural and food engineering. In this area many problems involve fluid flow, heat and mass transfer and mechanics. Typical examples include mixing, drying, sterilization, chilling in food industry; design and building of animal housing, ventilation and design of greenhouses in structures and environment engineering; roll-over protective structure designs and tyre-soil contact in power and machinery area.

An extensive bibliographic research was made through the more relevant scientific journals in order to highlight the fields and the better documented or more promising applications of numerical modelling.

The bibliographic database used was Scopus that is the largest abstract and citation database of peer-reviewed literature and quality web sources with smart tools to track, analyze and visualize research [http://www.info.sciverse.com/scopus/about/]. The principal strong points of Scopus are summarized in Table 1 (at 2011):

\begin{tabular}{l}
\hline Contains 41 million records, $70 \%$ with abstracts \\
\hline Nearly 18,000 titles from 5,000 publishers worldwide \\
\hline $70 \%$ of content is pulled from international sources \\
\hline Includes over 3 million conference papers \\
\hline Offers sophisticated tools to track, analyze and visualize research
\end{tabular}

TABLE 1 - Strong points of the database Scopus.

The search keywords used to carry on the present study were: numerical simulation, finite element, $C F D$, computational fluid dynamics, finite volume, numerical modelling and numerical model.

Restricting the research area to agri-food engineering a total of about 12,000 scientific works was found, spanning from early the ' 60 s to 2011 .

In Figure 2 is reported the number of papers issued for year, where data show an exponential growth. The data relative to year 2011 is estimated on the base of the first half year.

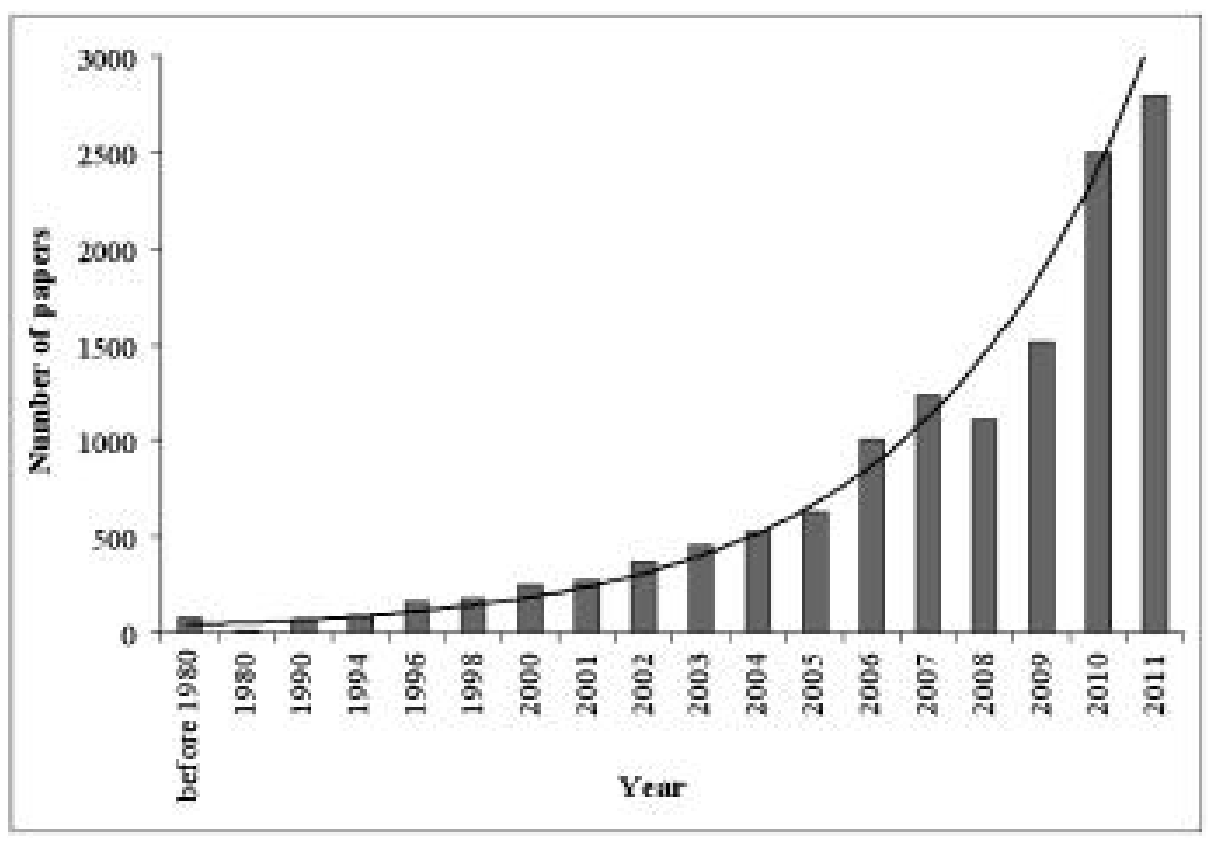

Fig. 2 - Number of published papers on numerical simulation in agri-food engineering. 
The papers derive from different source type: journal $(96 \%)$, conference proceeding $(3 \%)$, book series $(1.5 \%)$ and trade publication $(0.5 \%)$. The most number of papers is written in English (88\%), but it must be observed that about $10 \%$ is written in the Chinese language.
In Table 2 the list of the most important journals consulted is reported. The list order reflects the number of papers found, that decrease from journal $n^{\circ} 1$ (Journal of Theoretical Biology) to journal n¹19 (Irrigation Science). In parentheses is reported the number of publications on the numerical simulation.

\begin{tabular}{|c|c|c|c|}
\hline 1 & Journal of Theoretical Biology (823) & 61 & International Journal of Heat and Technology (53) \\
\hline 2 & Water Resources Research (674) & 62 & Biosystems Engineering (52) \\
\hline 3 & $\begin{array}{l}\text { Yanshilixue Yu Gongcheng Xuebao Chinese Journal of } \\
\text { Rock Mechanics and Engineering (533) }\end{array}$ & 63 & Journal of Loss Prevention in the Process Industries (51) \\
\hline 4 & Journal of Hydrology (474) & 64 & Bioresource Technology (49) \\
\hline 5 & Continental Shelf Research (377) & 65 & Biological Conservation (46) \\
\hline 6 & Mathematical Biosciences (323) & 66 & Journal of Geophysical Research G Biogeosciences (46) \\
\hline 7 & Yantu Lixue Rock and Soil Mechanics (322) & 67 & Plant and Soil (44) \\
\hline 8 & $\begin{array}{l}\text { Nongye Jixie Xuebao Transactions of the Chinese } \\
\text { Society of Agricultural Machinery (279) }\end{array}$ & 68 & Soil Science (43) \\
\hline 9 & Estuarine Coastal and Shelf Science (242) & 69 & Aquaculture (42) \\
\hline 10 & Ecological Modelling (233) & 70 & Journal of Evolutionary Biology (40) \\
\hline 11 & Journal of Marine Systems (231) & 71 & Agriculture Ecosystems and Environment (39) \\
\hline 12 & Geotechnical Special Publication (177) & 72 & Ecography (39) \\
\hline 13 & Journal of Food Engineering (167) & 73 & Chinese Journal of Ecology (39) \\
\hline 14 & Biometrics (158) & 74 & Oceanologica Acta (37) \\
\hline 15 & Vadose Zone Journal (157) & 75 & Canadian Journal of Fisheries and Aquatic Sciences (37) \\
\hline 16 & Journal of Irrigation and Drainage Engineering (139) & 76 & Environmental Geology (37) \\
\hline 17 & Soil Science Society of America Journal (134) & 77 & Journal of Plankton Research (37) \\
\hline 18 & $\begin{array}{l}\text { Proceedings of the Royal Society B Biological Sciences } \\
\text { (130) }\end{array}$ & 78 & American Journal of Agricultural Economics (35) \\
\hline 19 & Shengtai Xuebao Acta Ecologica Sinica (129) & 79 & European Journal of Forest Research (35) \\
\hline 20 & Transactions of the Asabe (123) & 80 & Acta Biotheoretica (35) \\
\hline 21 & Acta Oceanologica Sinica (117) & 81 & New Phytologist (34) \\
\hline 22 & Agricultural Water Management (115) & 82 & Oceanologia (34) \\
\hline 23 & Soil Dynamics and Earthquake Engineering (112) & 83 & Diversity and Distributions (34) \\
\hline 24 & Bulletin of Mathematical Biology (105) & 84 & Fisheries Oceanography (34) \\
\hline 25 & Agricultural and Forest Meteorology (104) & 85 & Mathematical Biosciences and Engineering (33) \\
\hline 26 & $\begin{array}{l}\text { Nongye Gongcheng Xuebao Transactions of the } \\
\text { Chinese Society of Agricultural Engineering (103) }\end{array}$ & 86 & Water Environment Research (33) \\
\hline 27 & International Journal of Refrigeration (102) & 87 & Journal of Experimental Biology (33) \\
\hline 28 & Computers and Electronics in Agriculture (101) & 88 & Plos One (33) \\
\hline 29 & Theoretical Population Biology (94) & 89 & $\begin{array}{l}\text { International Journal of Environmental Science and } \\
\text { Technology (32) }\end{array}$ \\
\hline 30 & Marine Ecology Progress Series (94) & 90 & Applied and Environmental Microbiology (32) \\
\hline 31 & Geotechnical and Geological Engineering (92) & 91 & Soil Biology and Biochemistry (31) \\
\hline 32 & Environmental Earth Sciences (91) & 92 & Agricultural Systems (31) \\
\hline 33 & Journal of Mathematical Biology (86) & 93 & Journal of Biogeography (31) \\
\hline 34 & International Journal of Geomechanics (85) & 94 & Journal of Animal Ecology (30) \\
\hline 35 & $\begin{array}{l}\text { Transactions of the American Society of Agricultural } \\
\text { Engineers (85) }\end{array}$ & 95 & Journal of Great Lakes Research (29) \\
\hline 36 & Marine Pollution Bulletin (82) & 96 & Journal of Soil and Water Conservation (29) \\
\hline 37 & Geoderma (82) & 97 & International Journal of Sediment Research (28) \\
\hline 38 & Forest Ecology and Management (77) & 98 & Estuaries (28) \\
\hline
\end{tabular}




\begin{tabular}{|c|l|c|l|}
\hline 39 & $\begin{array}{l}\text { Deep Sea Research Part I Oceanographic Research } \\
\text { Papers (76) }\end{array}$ & 99 & Agricultural Economics (27) \\
\hline 40 & $\begin{array}{l}\text { Deep Sea Research Part II Topical Studies in } \\
\text { Oceanography (76) }\end{array}$ & 100 & Oecologia (27) \\
\hline 42 & Biomass and Bioenergy (71) & 102 & South African Journal of Science (26) \\
\hline 43 & Hydrobiologia (70) & 103 & Pedosphere (26) \\
\hline 44 & $\begin{array}{l}\text { Philosophical Transactions of the Royal Society B } \\
\text { Biological Sciences (70) }\end{array}$ & 104 & Aquacultural Engineering (25) \\
\hline 45 & Ecology (68) & 105 & Behavioural Processes (25) \\
\hline 46 & Evolution (66) & 106 & Current Science (25) \\
\hline 47 & Chinese Journal of Applied Ecology (64) & 107 & Evolutionary Ecology (25) \\
\hline 48 & American Naturalist (63) & 108 & Population Ecology (25) \\
\hline 49 & Biosystems (62) & 109 & Paddy and Water Environment (25) \\
\hline 50 & Progress in Oceanography (62) & 110 & Eurasian Soil Science (24) \\
\hline 51 & Acta Horticulturae (61) & 111 & Applied Geography (24) \\
\hline 52 & Biogeosciences Discussions (60) & 112 & Quaternary Science Reviews (24) \\
\hline 53 & Biogeosciences (59) & 113 & Aiche Journal (24) \\
\hline 54 & Canadian Journal of Forest Research (57) & 114 & Biology Letters (24) \\
\hline 55 & European Journal of Soil Science (57) & 115 & Paper American Society of Agricultural Engineers (23) \\
\hline 56 & ICES Journal of Marine Science (57) & 116 & Oikos (23) \\
\hline 57 & Journal of Biological Systems (57) & 117 & Mathematical Population Studies (23) \\
\hline 58 & $\begin{array}{l}\text { Journal of Agricultural Biological and Environmental } \\
\text { Statistics (57) }\end{array}$ & 118 & Wood Science and Technology (23) \\
\hline 59 & Limnology and Oceanography (54) & & \\
\hline 60 & Remote Sensing of Environment (54) & Irigation Science (23) \\
\hline
\end{tabular}

TABLE 2 - List of the most important journal that publish on numerical simulation in agri-food engineering.

In Table 3 are listed the first 40 institutions involved in numerical simulation research; in parentheses is reported the number of publications.

Grouping the institutions on a geographic criteria, it arises that $45 \%$ of them are located in USA and Oceania, $31 \%$ in EU and Russia and $23 \%$ in China and India. The first italian institutions, with about 30 publications each, are: Consiglio Nazionale della Ricerca (CNR), Università degli Studi di Napoli Federico II and Alma Mater Studiorum Università di Bologna.

The most popular numerical simulation software packages are reported in Table 4, in decreasing order of citations.

The papers were also classified in the following four thematic classes, on the base of keywords reported by authors:

1 - application to agricultural water management (e.g soil water retention, irrigation): $\approx 25 \%$;

2 - design and structural application in agricultural architecture (e.g. farm and greenhouse): $\approx 20 \%$;

3 - structural applications in agricultural machinery construction (e.g. design of tractors mechanical parts, roll-over protective structures assessment), soil mechanics and interaction with tyres and tillage tools: $\approx 20 \%$;
4 - application in food engineering (e.g. treatment such as freezing, pasteurization, mixing, sterilization by electromagnetic waves, or industrial plant design): $\approx 15 \%$;

5 - others applications: $\approx 20 \%$.

Some surveys on the application of numerical simulation in agri-food were found in literature. Most of them regard the applications to food industry [Norton 2006; Wang 2003; Gerlach 2008; Scott 1997; Kuriakose 2010].

It is notable that in 2002 the Computers and Electronicd in Agriculture published an entire volume (14 papers) on the item Computational Fluid Dynamics a design and analysis tool for the agri-food industry. The topics covered included ventilation and design of greenhouse and farm buildings, heating, cooling and storage of agricultural and food products, analysis and optimisation of food processes and facilities.

Moreover the Journal of Food Engineering in the year 2005 published an interesting special section on finite element modelling grouping different research on: microwave heating of foodstuff, pasta drying, transport phenomena in membrane concentration, food fluid, mixing, ultrafiltration of fruit juice, roasting of grain, infrared drying and cooking and fish cooling. 


\begin{tabular}{|l|l|}
\hline Chinese Academy of Sciences (186) & UC Davis (116) \\
\hline University of Oxford (103) & University of Tokyo (100) \\
\hline Wageningen University (90) & Katholieke Universiteit Leuven (90) \\
\hline University of Florida (86) & Dalian University of Technology (83) \\
\hline Texas A and M University (82) & Woods Hole Oceanographic Institution (81) \\
\hline Cornell University (79) & Jiangsu University (79) \\
\hline China Agricultural University (77) & North Carolina State University (76) \\
\hline The University of British Columbia (74) & CNRS Centre National Recherche Scientifique (73) \\
\hline University of Washington Seattle (73) & Kyushu University (70) \\
\hline Zhejiang University (67) & USDA Agricultural Research Service, (66) \\
\hline Wageningen University Research Centre (66) & UC Berkeley (66) \\
\hline Oregon State University (65) & Imperial College London (65) \\
\hline Tongji University (65) & Hohai University (64) \\
\hline United States Geological Survey (64) & China University of Mining Technology (64) \\
\hline Kyoto University (63) & Eidgenossische Technische Hochschule Zurich (63) \\
\hline Pennsylvania State University (62) & University of Western Australia (61) \\
\hline University of Wisconsin Madison (60) & Purdue University (59) \\
\hline Tsinghua University (58) & University of California, Riverside (58) \\
\hline University of Sydney (57) & Wuhan University (57) \\
\hline University of Nebraska - Lincoln (56) & Proudman Oceanographic Laboratory (55) \\
\hline & \\
\hline
\end{tabular}

TABLE 3 - List of the most important institutions that published on numerical simulation in agri-food engineering more than 55 publications in the period 1960-05/2011.

\begin{tabular}{|l|l|l|}
\hline Name & Company & Type \\
\hline Fluent & Fluent Inc, www.ansys.com & TFD \\
\hline Comsol-Femlab & Comsol Inc, www.comsol.com & MP \\
\hline ANSYS & ANSYS Inc, www.ansys.com & MP \\
\hline CFX & ANSYS Inc, www.ansys.com & TFD \\
\hline STAR-CD & CD Adapco Group, www.cd-adapco.com & TFD \\
\hline PHOENICS & CHAM Ltd, www.cham.co.uk & TFD \\
\hline ADINA & ADINA Inc, www.adina.com & MP \\
\hline
\end{tabular}

Note: TDF: Thermo Fluid Dynamics Software; MP: Multiphysics Sftware

TABLE $\quad 4$ - List of the most popular numerical simulation software.

The growing trend of number of scientific studies involving aspects of numerical modelling highlights the development potential of the method in agri-food industry. Moreover it was possible to observe that

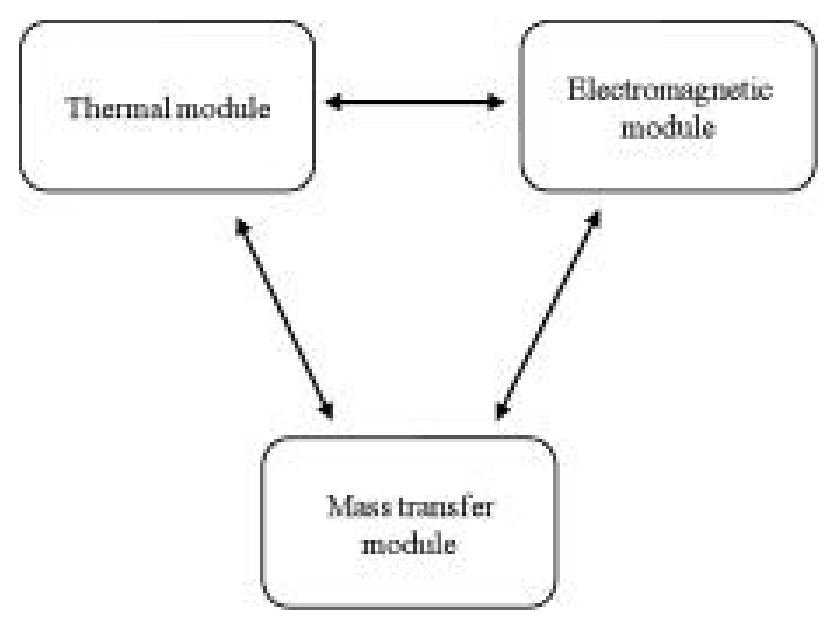

Fig. 3 - Scheme of the physical interactions for an electromagnetic heating model. modelling activity evolves toward a higher complexity, in the sense that every single model tends to consider different physical aspects. This trend is permitted by the more modern software packages, which are actually moving towards codes characterized by the goal of so-called multiphysics. In other words multiphysics stay for the ability to manage different physical aspects of a model, coupled together, even in a strongly nonlinear way.

As an example in figure 3 is considered the case of microwave heating. The electromagnetic field is influenced by the moisture distribution inside the body and mutually interacts with the thermal effects. The moisture distribution depends on the thermal field and air flow around the body, and so on in a fully coupled way.

This result is reflected by behaviour of the current major manufacturer that are incorporating and integrating software companies that produce specialized codes.

\section{Conclusion}

The scientific literature is a witness of the considerable development, in recent years, of numerical simulation techniques and their possible applications to the solution of many physical problems. In particular, with regard to agricultural and food engineering, numerical simulation has been proven as a tool that can significantly reduce costs of experimentation and prototyping. This although, unfortunately, the specific industrial sector tends to update slowly.

The method is not inherently limited, but limits have to be found in hardware availability and in the possibility, by the designer, to describe in deep the 
most significant physical details of the problems to be simulated. The use of a commercial software package does not transform the modelling activity in a trivial operation. In fact it involve the creative ability to reduce the physical reality in a model, considering even the different specific features of each computer code. Numerical simulation techniques are destined to a wider spread, as a consequence of the increasing complexity of plant and processes and of continuous reduction of computing power cost. Currently the main obstacle to diffusion is the high technical and scientific skill required by operators, which is actually compensated in many factories with outsourcing resources. However, it is possible to observe, as an index of increasing interest, that numerical simulation techniques are spreading in academic engineering courses, and moreover many software producers offer low budget policies for learning purposes.

The FE/FV codes are more and more stable, economical and easy to use. The cost of the software may seem sometimes high, but it should be realistically compared with that of an experimental investigation.

\section{References}

Datta A.K, Sun E., Solis A., Food Property Data and Their Composition-Based Prediction, in Engineering Properties of Foods, M.A. Rao and S.S.H. Rizvi. eds. 1995, Marcel Dekker, New York.

Datta A.K., Computer-Aided Engineering in Food Process and Product Design. Food Technology, 1998, 52, 44-52.

EngineeringToolbox, 2011, http://www.engineeringtoolbox.com/material-properties-24.html

ESM Software, Inc., 2011, http://www.esm-software.com

Gerlach D., Alleborn N., Baars A., Delgado A., Moritz J., Knorr D., Numerical simulations of pulsed electric fields for food preservation: A review. Innovative Food Science and Emerging Technologies, 2008, 9, 408-417.

Goodfellow Cambridge Limited, 2011, http://www.goodfellow.com

Houska M., Nesvadba P., Mayer Z., Database of physical properties of foods: Subgroup of mechanical and rheological Properties. Journal of Texture Studies, 2001, 32, 155-160.

Kuriakose R., Anandharamakrishnan C., Computational fluid dynamics (CFD) applications in spray drying of food Products. Trends in Food Science \& Technology, 2010, 21, 383-398.

MatWeb, Automation Creations, Inc., Blacksburg, Virginia. 2011, http://www.matweb.com

Mohsenin N.N., Thermal Properties of Foods and Agricultural Materials, Gordon and Breach Science Publishers Inc. 1980, New York.

Nelfood, Database of Physical Properties of Food, Food Properties Awareness Club. 2011, http://www.nelfood. $\mathrm{com} /$
Nesvadba P., Houska M., Wolf W., Gekas V., Jarvis D., Sadd P.A., Johns A.I., Database of physical properties of agro-food materials. Journal of Food Engineering, 2004, 61, 497-503.

Norton T., Sun D.W., Computational fluid dynamics (CFD) $\mathrm{e}$ an effective and efficient design and analysis tool for the food industry: A review. Trends in Food Science \& Technology, 2006, 17, 600- 620.

Okos M.R., Physical and Chemical Properties of Food, American Society of Agricultural Engineers, 1986, St. Joseph, Michigan.

Puri V.M., Anantheswaran, R.C., The finite-element method in food processing: a review. Journal of Food Engineering, 1993, 19, 247-274.

Puri V.M., Anantheswaran R.C., Finite Element Method in Food Processing: A Review. 1990, Paper 90-6523, ASAE, St. Joseph, MI.

Rahman M.S., Food Properties Handbook, Second Edition, 2009, Boca Raton, Florida, USA: CRC Press.

Rao M.A., Datta A.K. and. Rizvi S.S.H., Engineering Properties of Foods, Third Edition, 2005, Boca Raton, Florida, USA: CRC Press.

Rao M.A., Rizvi S.S.H., Engineering Properties of Foods, Marcel Dekker Inc., 1995, New York.

Scott G., Richardson P., The application of computational fluid dynamics in the food industry. Trends in Food Science \& Technology, 1997, 8, 119-124.

Singh R.P., Food Properties Database v2.0 for Windows. 1995, Boca Raton, Florida, USA: CRC Press .

Singh R.P., Medina A.G., Food Properties and ComputerAided Engineering of Food Processing Systems. 1989, Boston, MA: Kluwer Academic Publishers.

Wang L., Sun D.W., Recent developments in numerical modelling of heating and cooling processes in the food industry e a review. Trends in Food Science and Technology, 2003,14, 408-423.

\section{SUMMARY}

In agri-food engineering many complex problems arise in plant and process design. Specifically the designer has to deal with fluid dynamics, thermal or mechanical problems, often characterized by physics coupling, non-linearity, irregular geometry, anisotropy and in definitive rather high complexity. In recent years, the ever growing availability of computational power at low cost, made these problems more often approached with numerical simulation techniques. Mainly in terms of finite elements and finite volumes.

In this paper the fundamentals of numerical methods are briefly recalled and a discussion about their possibility of application in the food and agricultural engineering is developed.

Keywords: agri-food engineering, numerical simulation, finite elements, numerical modelling. 
001_Fabbri(598)_01 27-01-2012 15:04 Pagina 8 